\title{
JUVENTUDE(S) E ENSINO MÉDIO: DA INCLUSÃO ESCOLAR EXCLUDENTE AOS JOVENS CONSIDERADOS NEM-NEM
}

\author{
YOUNG PEOPLE AND SECONDARY SCHOOL: FROM AN EXCLUDING SCHOOL INCLU- \\ SION TO YOUNG PEOPLE CONSIDERED NEITHER-NOR \\ JUVENTUD(ES) Y ENSEÑANZA SECUNDARIA: DE LA INCLUSIÓN ESCOLAR EXCLUY- \\ ENTE A LOS JÓVENES CONSIDERADOS NINI
}

Márcio Luiz Bernardim ${ }^{1}$ Monica Ribeiro da Silva²

${ }^{1}$ Doutor em Educação pela Universidade Federal do Paraná (UFPR) - Curitiba - PR - Brasil. ${ }^{2}$ Doutora em Educação pela PUC/SP. Docente do Programa de Pós-Graduação em Educação da Universidade Federal do Paraná (UFPR) - Curitiba - PR - Brasil.

Resumo: Neste estudo discorremos sobre as tensões que marcam a(s) juventude(s) no século 21 e suas inter-relações com o processo educativo escolar. Retomamos as principais correntes teóricas que versam sobre o conceito de juventude, analisando as limitações das abordagens que a consideram como um sujeito idealizado e destituído de materialidade histórica. Ao demonstrar a amplitude e demarcar a compreensão da categoria juventude, discutimos as condições e as expectativas acerca do Ensino Médio a partir dos dados primários coligidos, concluindo com a análise das relações entre escola e trabalho e das dificuldades enfrentadas pelos jovens diante do universo escolar. Tanto a pluralidade que caracteriza a condição juvenil quanto as formas de manifestação da subjetividade dimensionam o desafio que é compreender hoje a(s) juventude(s) em sua dinâmica relação com a escola.

Palavras-chave: Juventude e Ensino Médio; Juventude, escola e trabalho; Jovens nem-nem.

Abstract: This study discusses the tensions that mark young people of the $21^{\text {st }}$ century, and their interrelations with the school education process. The main theoretical trends that focus on the concept of youth are summarized, analyzing the limitations of the approaches that consider it an idealized subject devoid of historic materiality. In demonstrating the breadth and delimiting the understanding of the category "young people," the conditions and expectations concerning Secondary School are discussed based on the the primary data collected, concluding with an analysis of the relations between school and work and the difficulties faced by young people faced with the school universe. Both the plurality that characterizes the condition of being a young person, and the forms of manifestation of subjectivity, project the dimensions of the challenges of understanding young people today, in their dynamic relationship with the school.

Key words: Youth and Secondary School; Youth, school and work; Neither-nor young people.

Resumen: En este estudio discurrimos sobre las tensiones que marcan a la(s) juventud(es) en el siglo XXI y sus interrelaciones con el proceso educativo escolar. Retomamos las principales corrientes teóricas que versan sobre el concepto de juventud, analizando las limitaciones de los abordajes que conciben al joven como un sujeto idealizado y destituido de materialidad histórica. Al demostrar la amplitud y demarcar la comprensión de la categoría "juventud", discutimos las condiciones y expectativas acerca de la Enseñanza Secundaria a partir de los datos primarios reunidos y concluimos 
con el análisis de las relaciones entre escuela y trabajo y de las dificultades enfrentadas por los jóvenes ante el universo escolar. Tanto la pluralidad que caracteriza la condición juvenil como las formas de manifestación de la subjetividad dimensionan el reto que implica comprender hoy a la(s) juventud(es) en su dinámica relación con la escuela.

Palabras clave: Juventud y Enseñanza Secundaria; Juventud, Escuela y Trabajo; Jóvenes nini.

\title{
INTRODUÇÃO
}

\author{
Encontra-se aí o significado essencial que tem hoje \\ "ser jovem": é não ter nada a perder e ser para si mesmo \\ apenas indefinidas possibilidades a realizar; é não ter \\ propriedade, nem aquisições, nem interesses a defender \\ [...] e, como consequência, não ter outro ponto de vista \\ sobre o mundo que o de suas próprias exigências [...].
}

(GORZ, 2009, p. 27)

Um simples olhar sobre a escola de Ensino Médio hoje nos mostra que os jovens que a frequentam têm especificidades que nem sempre são consideradas e/ou adequadamente compreendidas no contexto das políticas públicas voltadas à inserção escolar.

Este artigo apresenta o resultado de estudos sobre a juventude a partir da sua especificidade que vai além dos sentidos que lhe são frequentemente associados. Em geral os discursos tomam a vida humana como um conjunto de etapas distintas e estanques e situam os jovens na mais curta e menos importante delas.

A juventude ou as juventudes aqui referidas são aquelas que se caracterizam pela busca de uma identidade própria e que se expressam pela mediação da escola e do trabalho. Nesse sentido, nosso objetivo não é a juventude em si, mas os jovens que insistem, apesar das dificuldades socioeconômicas, em construir seus projetos de vida "na" e "pela" escola de Ensino Médio. A partir dessa perspectiva, propomo-nos a discutir a presença e/ou a ausência juvenil na escola.

Tendo em vista essa intencionalidade, organizamos o artigo em três seções, que abordam a juventude e o sentido de ser jovem no século XXI, a negação da condição juvenil e a realidade dos jovens que estudam e dos que não estudam e não trabalham (nem-nem). Tal divisão tem o objetivo de compreender os sujeitos jovens a partir das suas relações com a escola e com o trabalho. $O$ artigo resulta de pesquisa bibliográfica que permitiu, a partir da compreensão sociológica da juventude, analisar dados da inserção juvenil no sistema escolar brasileiro considerando as estatísticas oficiais. Em síntese, do estudo realizado, nos foi possível concluir que a ampliação do acesso à última etapa da Educação Básica se encerra no que podemos chamar de inclusão escolar excludente.

\section{A juVEntude e o SEntido de SER JOVem no século XXI}

Dedicar algum tempo à compreensão do conceito de juventude impõe-se hoje como uma tarefa necessária, ainda que de difícil realização, haja vista o ritmo das transformações 
na sociedade e a complexidade dessa categoria, cuja abordagem subentende inúmeras perspectivas considerando, inclusive, a área do conhecimento em que se insere a análise.

Por muito tempo imperou a compreensão da juventude a partir dos fatores biológicos e psicológicos característicos da fase da vida que transita entre a infância e a vida adulta. Essa caracterização partia da observação de ocorrências mais ou menos típicas ou característicaspadrão relacionadas às alterações orgânicas que marcam esse período.

Num amplo estudo que fez a partir da produção científica sobre juventude e educação no Brasil, Sposito (2000) recupera as principais referências conceituais sobre a juventude e destaca que a classificação restrita à transitoriedade etária merece crítica por dois aspectos relevantes: i) pela caracterização da transição como algo indeterminado, quando o indivíduo ainda não é adulto e já deixou de ser criança; ou seja, o jovem estaria se constituindo em outro ser. Esse percurso da vida, cada vez mais alongado, estaria desqualificado por se constituir em uma mera passagem; ii) pela subordinação dessa fase à vida adulta, que funcionaria como referência normativa de estabilidade em contraste com a instabilidade e as crises do período juvenil. Também essa compreensão estaria, hoje mais do que antes, comprometida pelo caráter instável e turbulento que marca a vida toda, e não só a juventude.

No campo da sociologia, Galland apud Silva e Andrade (2009) caracteriza os estudos sobre juventude em duas correntes: geracional e classista. Apesar disso, reconhece não haver homogeneidade na tomada conceitual inclusive entre os estudiosos de cada uma dessas correntes.

Com maior participação de autores de viés funcionalista, a corrente geracional tomaria a juventude pelo seu recorte etário e trataria a questão da condição juvenil como um quadro homogêneo que, no limite dos conflitos, valores e descontinuidades, poderia suscitar subculturas juvenis. Já para a corrente classista, marcada pelos estudos de autores marxistas, a preocupação não estaria necessariamente nas culturas juvenis, mas sim nas soluções que os jovens de uma classe compartilham. A juventude não poderia ser homogeneizada pela idade, mas pela possibilidade histórica da emergência da transformação.

Mesmo que haja uma tendência, nos estudos e nas políticas públicas destinadas aos jovens, de tomar como referência uma faixa etária específica, também com relação a isso não há consenso. O mais comum é que sejam classificadas como jovens as pessoas com idade entre 15 e 24 anos, não deixando de considerar também, segundo estudos europeus (Pais, 2001), que essa faixa tem sido dilatada para contemplar indivíduos com até trinta anos ou mais. De toda sorte, no âmbito da Organização das Nações Unidas (ONU), continua sendo considerada juvenil a população que vai dos 15 aos 24 anos de idade (DAYRELL; REIS, 2010).

No Brasil muitas discussões foram feitas em torno da redefinição da população considerada jovem. Depois da inserção do termo "juventude" na Constituição Federal e da definição da faixa etária dos 15 aos 29 anos, recentemente foi sancionado o Estatuto da Juventude, Lei n. 12.852 (BRASIL, 2013), cujo texto assegura aos jovens, entre outros, os seguintes direitos:

Art. $7^{\circ} \mathrm{O}$ jovem tem direito à educação de qualidade, com a garantia de educação básica, obrigatória e gratuita, inclusive para os que a ela não tiveram acesso na idade adequada. 
Art. $9^{\circ} \mathrm{O}$ jovem tem direito à educação profissional e tecnológica, articulada com os diferentes níveis e modalidades de educação, ao trabalho, à ciência e à tecnologia, observada a legislação vigente.

Assim, as preocupações em torno da ampliação do tempo etário jovem têm relação com o aumento da expectativa de vida da população e com as dificuldades de ordem socioeconômica que acompanham esse público e postergam a sua autonomia em relação aos adultos.

Antes mesmo da aprovação do Estatuto da Juventude, as políticas públicas já vinham ampliando a faixa etária dos estratos sociais a serem contemplados, demonstrando sensibilidade na identificação de demandas comuns a um público de espectro mais amplo. Exemplo disso foi o lançamento do ProJovem Integrado, em setembro de 2007, que abrigava uma série de programas até então dispersos entre os Ministérios e Secretarias de Estado, com a novidade de abranger o público de 15 aos 29 anos, de acordo com as modalidades em que o Programa se subdivide (SILVA; ANDRADE, 2009).

Essa ampliação da faixa etária que compreende a fase juvenil reflete as alterações nos padrões, na conformação familiar e na independência dos filhos em relação aos pais. 0 estudo sobre a constituição familiar e a formação de novas moradias, realizado pelo Instituto de Pesquisas Econômicas Aplicadas (IPEA, 2012), mostra que mesmo havendo redução da dependência financeira dos jovens em relação aos pais, nos últimos anos tem-se verificado uma postergação da emancipação domiciliar. Esse mesmo relatório também apresenta uma análise de estudos internacionais sobre o tema, destacando que, de todas as possíveis variáveis usualmente utilizadas para compreensão da dinâmica da independência dos jovens em relação aos pais, a mais sensível é a variável gênero.

Assim, ainda conforme o Comunicado do IPEA (2012), as mulheres saem mais cedo de casa, principalmente para constituir família, enquanto os homens são mais influenciados pelo perfil econômico dos pais ou responsáveis e do país no qual vivem. Todavia, não há consenso se os pais com renda mais alta atuam para reter os filhos por mais tempo em casa ou para auxiliá-los na transição mais tranquila para uma vida domiciliar independente.

No estudo que analisa a parcela dos jovens brasileiros, de 15 a 29 anos, que não estudam e nem trabalham, Camarano e Kanso (2012) trazem elementos que contribuem para analisar essa relação não determinística entre a renda dos jovens e a constituição familiar original. Os números apresentados revelam que o rendimento médio per capita dos domicílios que têm jovens nessa condição (que não estudam e nem trabalham) é menos da metade ( $R \$ 418,55)$ da renda dos domićlios dos jovens que estudam e trabalham ( $R \$ 854,77$ ). Logo, a renda dos jovens pode tanto encaminhá-los para a independência financeira em relação aos pais, com a constituição de um novo domicílio, quanto postergar essa transição. Da mesma forma, a falta de renda pode fixar os jovens no domicílio, ou apressar a sua saída em situação de grande vulnerabilidade socioeconômica. Há ambiguidade nos estudos quanto ao impacto do ingresso no mercado de trabalho sobre a decisão de buscar a independência domiciliar. A literatura ratifica, no entanto, a ideia de que a independência financeira é uma condição necessária, mas não suficiente para a emancipação domiciliar dos jovens. 
Por fim, preocupado com a política habitacional, o estudo defende

... que a política habitacional tem que ser diversificada e deve levar em conta as variáveis relativas ao ciclo de vida. A população jovem necessita de uma oferta habitacional variada, a preços acessíveis e que atenda às suas necessidades de moradia e de mobilidade, seja ele um jovem estudante, trabalhador, estagiário, trainee, casado ou solteiro. (IPEA, 2012, p. 11 - grifo nosso).

Como podemos perceber, as políticas para a juventude precisam contemplar uma complexa teia de situações que condicionam e interferem na satisfação das necessidades dos sujeitos jovens, devendo enfrentar tanto as lacunas quanto o atendimento daquelas consideradas básicas, como a saúde e a moradia, até as relativas à inserção laboral digna, de modo a garantir uma transição segura para a autonomia financeira em relação à família e ao estado.

Nesse aspecto, o direito à educação profissional, incluído no Estatuto da Juventude, associado à ampliação da faixa etária dessa categoria, implica políticas públicas que sejam abrangentes, no sentido de alcançar a todos, independentemente de condição ou local de moradia, de gênero ou condição financeira. Isso não implica ignorar que, sob o capitalismo, as políticas públicas destinadas aos jovens devam ser orientadas para o atendimento daqueles que mais sofrem com o processo de marginalização inerente ao próprio sistema, a saber: os trabalhadores e, dentre eles, os mais pobres. Mas ainda que, no âmbito do Estado, sejam estabelecidos critérios etários para as políticas destinadas a esse público, eles devem servir como ponto de partida para captar as nuanças das especificidades que configuram as juventudes, mas não o limite que as condicione.

Um exemplo de outras possibilidades de classificação da juventude é o da perspectiva territorial. Soares (2011) opta por esse caminho ao estudar a relação entre os jovens e o mundo do trabalho, considerando o território um fator de criação de identidades. Para tanto não se limita a relacionar o isolamento ou o confinamento exclusivamente ao espaço físico, mas também os sentimentos que brotam desse distanciamento espacial periferia-centro. Para essa pesquisadora,

... nos discursos dos jovens, um certo enraizamento com o local de moradia aparece em frases contraditórias que ora ratificam um sentimento de pertencimento forte e identidade com o espaço e relações, ora reproduz o discurso de segregação com a favela muito recorrente na cidade do Rio de Janeiro. Por exemplo, a ideia comum sobre a indolência dos jovens, reproduzida entre eles mesmos, é algo fortalecido tanto no cotidiano, pela grande presença de jovens que estão fora da escola e sem oportunidades de trabalho que passam seus dias pelas ruas da comunidade, quanto pela legitimação de uma visibilidade social da juventude enquanto perigosa e potencialmente desviante. (SOARES, 2011, p. 227).

Nesse caso, se o sujeito jovem pode ser compreendido pela faixa etária, não menos importante é a combinação de fatores vinculados à condição e à localização da moradia, ao isolamento em relação a outros espaços urbanos e ao confinamento decorrente da infraestrutura de transporte e das limitações financeiras.

Inúmeras outras perspectivas podem ser utilizadas, de acordo com as áreas do conhecimento e/ou das opções ideológicas, mas o fato é que a compreensão da juventude no século XXI não permite uma resposta simples:

A combinação entre distintas maneiras de enxergar a questão juvenil colabora para a tentativa de responder à pergunta sobre quando alguém deixa de ser jovem e atinge a vida adulta. Essa resposta, que não pode ser dada definitivamente, depende tanto dos indicadores relativos às transformações vividas pelo corpo jovem biológico quanto 
daquilo que se refere aos dados sociais objetivos e às representações que cada sociedade empresta ao conceito de jovem e juventude. (CARRANO, 2010, p. 157).

Logo, limitar-se a considerar os jovens, de forma unilateral, pela idade, pela condição de classe ou pela identificação com o coletivo, não parece suficiente para compreender a juventude em toda a sua complexidade contemporânea. Implicaria ignorar o jovem como sujeito do seu tempo, que é fortemente guiado pelas exigências da sua natureza orgânica ou pelos condicionamentos socioculturais, mas que também se esquiva do "destino" que a sociedade procura impor-Ihe, reivindicando para si o protagonismo da sua própria história.

Não obstante a complexidade da tarefa, a apreensão conceitual da juventude passa, necessariamente, pela compreensão do significado que esta temática tem no contexto das relações sociais. Tal apreensão pressupõe a busca do sentido de ser jovem não pelo que isso parece ser ou pelo significado que a sociedade lhe atribui, mas principalmente pelo que é na realidade concreta.

A classificação de Galland apud Silva e Andrade (2009) auxilia na compreensão de como a sociedade veio classificando os jovens no tempo, em geral de acordo com sua relação com os adultos: da antiguidade até a alta idade média a partir de sua "relação de filiação"; no século XVIII como uma "relação educativa"; no século XIX mediante uma "relação intergeracional" e no século XX como um processo, primeiro de maturação psicológica, por influência dos estudos realizados nesse campo, e depois como processo de socialização.

Assim, chegamos ao século XXI na iminência de uma sociedade globalmente interconectada, em que as pessoas e, principalmente os jovens, se utilizam das novas tecnologias de comunicação para interagir, para discutir ideias, para organizar manifestações, elaborar projetos coletivos e se relacionar o tempo todo, independentemente de credo, nacionalidade, posição ideológica e classe e em amplitude incomparavelmente maior que as gerações anteriores.

Apesar de todos esses elementos apontados, que revelam uma possibilidade de maior compreensão da/s juventude/s, ela continua sendo apropriada no singular (uma juventude idealizada e homogênea) e analisada como uma categoria em construção, como um projeto, como um devir e não como uma realidade presente. Nos discursos políticos e no vocabulário econômico, os jovens são invariavelmente referidos pela potencialidade e pelo esplendor, normalmente sujeitos ao condicionamento social, simultaneamente às negativas que recebem por serem portadores de uma inquietude que "incomoda" e de um desejo genuíno de realização como sujeitos do seu tempo. Boa parte dos jovens confronta-se, portanto, com um passado de esperanças, um presente de grave vulnerabilidade material e de negação da subjetividade, e um futuro sem perspectivas de melhoria, conforme discorreremos a seguir.

\section{A NEGAÇÃO DA CONDIÇÃO JUVENIL}

Segundo o Mapa da Violência (WAISLFISZ, 2014), os jovens de 15 a 29 anos fazem parte do grupo etário mais suscetível à morte violenta, representando, em média, 45\% mais risco 
do que o restante da população brasileira. Diferentemente do que ocorria há cinco ou seis décadas passadas, em 2014 as principais causas de morte entre os jovens são decorrentes de violência, das quais mais de $60 \%$ estão associadas a homicídios.

De igual ou maior gravidade, além da violência vitimar muito mais os jovens quando comparados com os adultos, o índice de vitimização de jovens negros tem se ampliado, passando de 79,9 em 2002, para alarmantes 168,6 em 2012 (idem, p. 148): "para cada jovem branco que morre assassinado, morrem 2,7 jovens negros" (idem, p. 148). Isso demonstra que os números em geral, embora já preocupantes, podem sombrear uma realidade ainda muito mais perversa para as classes populares, que congregam os pobres e a maioria da população negra.

Além de se constituir em um grupo etário considerado apêndice do grupo hegemônico adulto, o que explica em parte a situação de abandono e o não alcance pelas políticas públicas, os jovens também são desrespeitados como componentes de uma categoria social que tem suas especificidades, como linguagem e valores próprios.

A pesquisa realizada pela BOX intitulada "Sonho Brasileiro" revelou que os jovens de 18 a 24 anos valorizam os seguintes aspectos relacionados à inserção profissional: carreira, carteira assinada e satisfação no trabalho. Perguntados sobre como eles percebem a opinião dos pais em relação ao mesmo assunto, as respostas revelaram inversões na ordem, aparecendo primeiro a carteira assinada e depois o salário; a satisfação no trabalho, todavia, sequer foi lembrada pelos pais (BOX, 2011). A pesquisa não apresenta detalhamento dos resultados por segmentos de público e/ou faixa de renda, mas a informação de que foi realizada com jovens de todas as classes de consumo e renda sinaliza para a expressão de uma realidade que perpassa a sociedade. Nesse sentido, mostra que, na relação intergeracional, os pais têm tido dificuldade de interpretar e/ou têm se negado a ouvir e buscar convergência entre as suas expectativas e os projetos e interesses dos filhos.

Conquanto afirmem ter uma boa relação familiar, os jovens dessa pesquisa declaram que os pais exercem muita pressão para optarem por carreiras profissionais mais "seguras" e que proporcionem maior retorno financeiro, conforme a manifestação de uma das entrevistadas:

Eu me formei como professora, eu vou ser sincera: eu adoro lecionar. Mas no almoço de domingo querem me convencer a fazer um concurso, até minha sogra me pede. Sei que há uma preocupação em relação à grana, mas eu acho que é também da sociedade porque é uma cobrança total. (BOX, 2011, p. 270).

A percepção de desvalorização da carreira docente manifestada no testemunho anterior, mesmo que aparentemente secundária para o nosso estudo, reverbera a falta de sinalização clara da sociedade e do Estado brasileiro quanto ao papel da educação escolar, e se reflete na pressão exercida sobre os projetos laborais dos jovens. Essa situação contribui para a valorização/desvalorização de determinadas ocupações em relação a outras e para a submissão de elementos que compreendem a formação da subjetividade jovem a condições de sociabilidade pautadas, exclusivamente, pela objetividade material, que se manifesta nas expectativas de melhores salários e segurança profissional dos adultos em detrimento da realização e da satisfação pessoal dos jovens.

A centralidade do trabalho não significa que o ser humano esgote na configuração que a sociedade lhe deu no atual momento histórico, mediante o exercício de ocupações laborais, 
todas as possibilidades de realização como ser social, pois há outras esferas de produção da existência e da sociabilidade para além do trabalho restrito, fragmentado e mercantil compreendido hoje como emprego:

Quanto mais se desenvolve o ser social, mais as suas objetivações transcendem o espaço ligado diretamente ao trabalho. No ser social desenvolvido, verificamos a existência de esferas de objetivação que se autonomizaram das exigências imediatas do trabalho - a ciência, a filosofia, a arte, etc. (NETTO; BRAZ, 2006, p. 43).

Assim, vale lembrar que, embora muitas pesquisas concentrem sua atenção na importância exclusiva do trabalho e da formação do sujeito para a produção e reprodução da existência humana, precisamos considerar o jovem e o adulto trabalhador como um ser complexo que não limita suas ações à constituição da sua materialidade, senão também da construção da sua estética, compreendida como o desejo de se expressar como sujeito do seu tempo.

Por certo que as necessidades materiais básicas continuarão a comandar as ações do sujeito até que possa razoavelmente satisfazê-las, restabelecendo o estágio de equilíbrio orgânico. É sobre esse campo bio-psíquico-comportamental que muitos estudos foram realizados durante todo o século XX, desde Maslow (2000), com os estudos que deram origem à Teoria das Necessidades Humanas; até Freud (1996), que revisou a sua tese sobre as pulsões de vida e de morte. Da mesma forma, à medida que tais necessidades ou pulsões vão se resolvendo, outras motivações, materiais ou imateriais, passam a orientar as iniciativas e os comportamentos do sujeito.

Nesse contexto, merecem atenção as políticas públicas que têm como foco a conclusão da Educação Básica e a preparação dos jovens para a inserção no mercado de trabalho. O Ensino Médio é hoje a última etapa da Educação Básica obrigatória, portanto, tem nos jovens o seu público prioritário e representa a base mínima e indispensável do caminho formativo escolar. Com a universalização desta base mínima, a sociedade republicana pretende assegurar o desenvolvimento das capacidades e a satisfação das necessidades, não apenas do ser humano isoladamente, mas do ser social, que vislumbra no horizonte da vida coletiva e solidária a expressão máxima da sua natureza sócio-histórica. Essa relação dos jovens trabalhadores com a escola e com o trabalho será abordada a seguir.

\section{A inclusão EXCLUdENTE de JOVENS QUE ESTUdAM E dOS QUE NEM ES-} TUDAM-NEM TRABALHAM

Entendemos que o estudo das relações entre a juventude, a escola e o trabalho precisa ser orientado, necessariamente, pela discussão do papel da escola na sociedade contemporânea e pela dimensão que toma o processo de escolarização de um enorme contingente de pessoas, parte das quais já inseridas no mercado de trabalho caracterizado por variadas formas de expropriação.

Ainda que as desigualdades sociais decorram de um sistema produtivo caracterizado pela propriedade privada dos meios de produção e pela divisão sociotécnica do trabalho, e estejam impregnadas no aparelho estatal e nas suas diversas organizações provedoras de 
serviços públicos (saúde, segurança, transporte, etc.), à instituição escolar continua sendo atribuíd o o papel hegemônico na formação e no desenvolvimento das condições indispensáveis à inserção socioeconômica, o que asseguraria uma participação na vida social, marcada hoje pelo globalismo internacional, pela competição intensa e pelo individualismo.

Ao receber os jovens oriundos da classe trabalhadora, que são atores sociais vitimados pela estrutura socioeconômica desigual, a escola não só abre perspectivas de enfrentamento dos efeitos do capitalismo mediante a democratização do seu espaço, como também afirma o sistema ao reproduzir as suas contradições, instaurando um tensionamento permanente entre a política e a execução, a intenção e a prática, o que se manifesta por meio de novos conflitos.

Essa fase histórica recente, marcada pelo acolhimento mais efetivo da classe trabalhadora na escola, ganhou força com o movimento que se convencionou chamar, nos anos 1990, de "reforma da educação", iniciado com a Lei n. 9.394/1996, que instituiu as Diretrizes e Bases da Educação Nacional (BRASIL, 1996). Embora essas Diretrizes não tenham refletido o caráter e as expectativas pelos quais os intelectuais comprometidos com os trabalhadores lutaram durante quase uma década de discussões e embates duros com os representantes do capitalismo imiscuídos no aparelho estatal ${ }^{1}$, elas tiveram um caráter indutor sobre as políticas públicas em educação, com resultados que, senão são os ideais, não podem ser ignorados.

No Comunicado 124, publicado pelo IPEA, há uma avaliação sobre os resultados obtidos com os programas e as ações das últimas duas décadas no plano educacional:

As matrículas cresceram em quase todos os níveis, etapas e modalidades educacionais. Além disso, notase também uma ampliação da ação relativa ao apoio ao educando, tanto no que diz respeito à introdução de novos tipos de benefícios, quanto na ampliação da quantidade de beneficiários atendidos. Este processo de ampliação da abrangência da política permitiu a inclusão de grupos populacionais cada vez maiores nas escolas e universidades, em condições que, se ainda longe das ideais, melhoraram nos últimos anos. Ademais, é importante mencionar que, apesar do processo recente de universalização do ensino, especialmente o básico e médio, ainda se nota déficit significativo de pessoas em idade escolar que, no entanto, não frequentam a escola. (IPEA, 2011b, p. 7).

Além do alerta do próprio Instituto sobre as limitações quantitativas em direção à essa universalização, também deve ser ponderado que as melhorias não são suficientes para dar conta do enorme desafio a ser enfrentado pela educação escolar, em especial porque a ampliação do acesso por si só não assegura a permanência dos estudantes e nem a terminalidade das etapas ou modalidades escolares acessadas, conforme observamos na persistência de altos índices de analfabetismo da população adulta e baixa taxa de conclusão do Ensino Médio, bem como nas diferenças de acesso, permanência e conclusão dos estudos, em todas as etapas escolares, o que guarda grande relação com a situação econômica familiar.

No caso do Ensino Médio, constatamos que os dados disponíveis mostram a universalização apenas como um ideal ainda muito longe de se concretizar em período próximo. A Pesquisa Nacional por Amostra de Domicílios (PNAD) de 2015 mostra que, se há melhora geral nos indicadores de escolarização, ela ainda não se reflete na incipiente taxa de frequência líquida à escola dos jovens de 18 a 24 anos, equivalente a 16\%, e dos jovens de 15 a 17 anos, equivalente 76 \%, contra 98\% da faixa de 7 a 14 anos. Se para esse último grupo etário a comparação dos dados indica uma melhora quantitativa a ser comemorada, visto que 
no início da década de 1990 a taxa não passava de 60\%, também precisamos considerar que a frequência é um indicador apenas relativo se não for associado à permanência, à conclusão e, em último caso, à qualidade social referenciada da etapa formativa vencida.

No que diz respeito especificamente ao Ensino Médio regular (excetuando a educação profissional e a educação de jovens e adultos), no ano de 2015 a matrícula totalizava 8,1 milhões, considerando todas as faixas etárias. Para os jovens entre 15 e 17 anos, que compõem a faixa escolar obrigatória, estavam matriculados pouco mais de $50 \%$ do corte etário. Próximo a 26\% (3,5 milhões) estavam ainda no Ensino Fundamental e não possuíam qualquer vínculo escolar, um total de 1,6 milhão de jovens (INEP, 2016).

Um dado que chama a atenção é a dificuldade de ultrapassarmos a barreira dos dez milhões de matrículas no Ensino Médio. Segundo dados da Sinopse Estatística da Educação Básica (INEP, 2014), a soma de todas as matrículas, independentemente de modalidade e tipo de oferta de Ensino Médio, chega a 10,4 milhões, dentre as quais 1,3 milhões na Educação de Jovens e Adultos (que acolhe um público em idade superior à considerada regular) e quase 800 mil na educação profissional subsequente (caso dos que já concluíram o Ensino Médio).

Com base nas Sinopses Estatísticas da Educação Básica (INEP 2005/2014), em se tratando ainda do Ensino Médio, na oferta regular verifica-se um aumento na participação dos alunos mais jovens (da faixa etária até os 17 anos) com redução significativa dos alunos com 18 anos ou mais. No caso da educação profissional, percebe-se um movimento inverso, ainda que não tão expressivo, de ampliação na participação de alunos acima de 24 anos, com redução na participação dos alunos das faixas inferiores. A EJA presencial apresenta um aumento na participação dos alunos até 24 anos e redução na participação dos alunos acima dessa idade.

A taxa de não aprovação (reprovação mais abandono) no Ensino Médio foi de 19,6\% em 2016. Essa é uma realidade que persiste e a desigualdade entre as unidades da federação reflete as desigualdades sociais e educacionais. Essa taxa variou entre 30\% (Alagoas) e 15\% (Santa Catarina). A distorção idade-série no Ensino Médio também é elevada: 28\% (INEP, 2016).

Em síntese, a matrícula no Ensino Médio, que era de pouco mais de 3,4 milhões em 1994, chega a 9 milhões em 2004 e passa a decrescer desde então, praticamente estabilizando em torno de 8 milhões e 300 mil matrículas entre 2008 e 2016 (INEP, 2016). A queda na matrícula entra em imediata contradição com o número de jovens entre 15 e 17 anos sem qualquer vínculo escolar: 1,6 milhões em 2016. O cenário que decorre dos dados analisados nos faz concordar com Kuenzer (2007) e, por isso, denominamos essa ampliação da oferta de "inclusão escolar excludente".

Além da problemática da não ampliação das matrículas no ritmo necessário para assegurar a todos os jovens o direito à conclusão da Educação Básica, outro aspecto que tem intrigado a todos que se debruçam sobre as questões educacionais é o que se refere ao grande contingente de jovens que não estudam e não trabalham.

No sugestivo estudo intitulado $O$ que estão fazendo os jovens que não estudam, não trabalham e não procuram trabalho?, Camarano e Kanso (2012) mostram que o número de jovens nessa condição vem aumentando nos últimos anos: entre os anos 2000 e 2010 variou 
de $16,9 \%$ para $17,2 \%$ do total de jovens. Mais mulheres do que homens têm deixado esse grupo, mas ainda assim elas representam $67,5 \%$ do montante de jovens que não estudam e não têm ocupação remunerada, basicamente devido ao arranjo familiar, à dedicação aos afazeres domésticos e ao cuidado dos filhos. O incremento dos jovens do sexo masculino entre os que não estudam e não trabalham, portanto, sugere "a necessidade de se elevar o número de oportunidades educacionais e profissionais para este grupo etário" (CAMARANO; KANSO, 2012, p. 38).

Esse índice de 17,2\% de jovens brasileiros que não estudam e nem trabalham era pior até do que os 16\% verificados nessa mesma condição na América Latina (HOPENHAYN, 2012). Situação que permanece ou se agrava, haja vista que no Brasil, no Chile, na Colômbia e no México, em 2016, era de 25\% o percentual de pessoas do sexo feminino entre 15 e 29 anos que não trabalham nem estudam e de $17 \%$ o percentual de pessoas do sexo masculino nesta condição (INEP, DEED, 2016).

A preocupação é com as consequências para esse grande contingente de jovens, as quais podem ser sentidas tanto na vulnerabilidade socioeconômica atual quanto nas perspectivas de agravamento da situação:
A breve análise realizada sugere que a escolaridade leva a uma participação maior nas atividades econômicas e, consequentemente, a uma renda mais elevada. Esta, por sua vez, afeta positivamente a frequência à escola. Isto leva a se perguntar se o baixo rendimento e a baixa escolaridade dos chefes onde residem os jovens que não estudavam e não estavam na força de trabalho não parecem capazes de ga- rantir-lhes uma preparação adequada para conseguirem uma posição satisfatória no mercado de trabalho. Por outro lado, não estar no mercado de trabalho resulta em um menor rendimento médio domi- ciliar per capita, o que deverá afetar a frequência à escola. Pergunta-se, portanto, se esses jovens, principalmente os do sexo masculino, estavam esperando por uma possibilidade de retorno à escola ou de ingresso (reingresso) no mercado de trabalho? Isto coloca a necessidade de políticas públicas que con- tribuam para uma inserção adequada desses jovens seja na escola ou no mercado de trabalho. (CAMAR- ANO; KANSO, 2012, p. 43 - grifo nosso).

A Pesquisa Nacional por Amostra de Domicílio mostrou que ano de 2015 aumentou para $22,5 \%$ o percentual de jovens entre 15 e 29 anos que não estuda e nem trabalha. Entre estes, 14,4\% não procuravam trabalho. A incidência é maior entre aqueles que possuem de 18 a 24 anos (IBGE, PNAD, 2015).

É difícil acreditar que um número tão expressivo de jovens que não está na escola e que também não está no mercado formal esteja efetivamente sem trabalhar. Afirmar que eles precisam do Ensino Médio noturno para sair dessa condição de inatividade econômica e educacional igualmente pode parecer um reducionismo. Todavia, a negativa dessa possibilidade não sinaliza um potencial de solução, tendo em vista a iminência do trabalho do jovem como fonte de renda para a própria sobrevivência ou da sua família.

O Brasil passou todo o século XX convivendo com um incipiente atendimento escolar da classe trabalhadora e esse não é efetivamente um fato novo. A novidade revelada pelos números é que, mesmo num momento em que todos os segmentos, desde o sistema produtivo, passando pelos organismos internacionais e chegando ao governo, apontam para a Educação Escolar Básica como uma necessidade indispensável para a inserção socioeconômica qualificada, a realidade insiste em desafiar as intenções e as políticas públicas nas quais elas se materializam. 
Apesar disso, tanto por conta da restrição de oferta no período noturno quanto em relação à dubiedade dos governos na implantação e no investimento no Ensino Médio, a expectativa de ampliar a escolarização dos jovens das classes populares vai esmorecendo. A indeterminação no tocante à educação profissional integrada ao Ensino Médio, que se arrasta por duas décadas, é um exemplo de insegurança no âmbito da política educacional e restringe o avanço na escolarização dos jovens, conforme análise de Lima Filho apud Dias (2011, p. 142):

Eu vejo que o último período, é um período de políticas públicas que no geral tem uma linha correta, que é o caminho da reintegração da educação profissional com a educação básica, mas é também um período de luzes e sombras, à medida que essa política, embora tenha uma diretriz acertada, não conta com aporte de recursos materiais, que deem prioridade para que ela seja levada às últimas consequências. Por que é que depois de sete anos do Decreto 5.154 que permite a reintegração, nós temos tão pouca educação profissional integrada ao Ensino Médio? Porque de fato faltam as condições materiais e a decisão política radical para levar isso adiante. Então nós vivemos, resumidamente, 20 anos de desmonte (1980 e 1990) e estamos agora num período de resistência e reconstrução, mas ainda bastante dúbio.

Os dados mostram que o público que ainda não concluiu ou não está cursando o Ensino Médio congrega um grande contingente de jovens, parte em idade regular e recém-concluinte do Ensino Fundamental e parte acima dessa idade (o que significaria para a escola distorção idade-série). Ambos fazem parte, majoritariamente, das classes populares, que precisaram tomar a decisão precoce de trabalhar ou de estudar. Nesse sentido, a possibilidade de atrair e acolher esses jovens trabalhadores passa necessariamente pela ampliação dos investimentos na educação profissional de caráter politécnico, na forma integrada ao Ensino Médio e oferta noturna, pelas redes públicas estaduais e federal.

A oferta noturna ganha ainda mais importância quando percebemos que, mesmo no caso de cursos de oferta integral, há estudantes que não podem prescindir da obtenção de alguma renda durante a fase de estudos. Foi isso o que constatou Steimbach (2012), quando pesquisou estudantes de colégios agrícolas do interior do Paraná. Segundo ele, mesmo em condições de internato, muitos alunos dependem da obtenção de alguma renda para manter-se ou para ajudar seus familiares. Assim, a realização de atividades esporádicas, como fotógrafos de fim de semana, auxiliares de pedreiro ou cortadores de cana, foi a forma encontrada para obter renda sem abandonar o curso.

Mesmo que os números do Ensino Médio não sejam aqueles esperados e estejam longe de se aproximar das metas estabelecidas no PNE 2014-2024, isso não quer dizer que o discurso sobre a importância da educação tenha perdido fôlego. Pelo contrário, as inúmeras alterações na legislação educacional e o discurso hegemônico apontam para a conclusão da Educação Básica como uma necessidade ou um desafio que não pode ser mais adiado.

CONSIDERAÇõES FINAIS

Os estudos realizados permitiram apresentar neste artigo, em forma de síntese, os elementos que contribuem para compreensão da/s juventude/s e da sua relação com a escola e o trabalho. 
Um dos primeiros problemas a ser enfrentado é a dificuldade que se tem de compreender a/s juventude/s sem situá-la/s no seu tempo e espaço. As abordagens teóricas tradicionalmente usadas nos diversos campos do conhecimento já não dão conta de explicar a complexidade que é ser jovem estudante e ser jovem trabalhador no século XXI.

As relações com a escola e com o trabalho acabam subdimensionadas se para a sua compreensão não considerarmos os elementos da prática social que se apresentam como limitadores e/ou potencializadores da realização da subjetividade dosjovens da classe trabalhadora na contemporaneidade. Em outras palavras, os jovens não podem ser estudados e compreendidos exclusivamente pela classificação etária ou mesmo pela condição de classe, senão pela totalidade complexa da sua subjetividade e pelo protagonismo que exercem na sociedade.

O passado de esperanças e o presente de vulnerabilidade socioeconômica para grande parte da juventude precisam ser tomados como elementos reveladores dos equívocos na compreensão e na abordagem da juventude e como ponto de partida para a criação de novas possibilidades, que devem contemplar não só a realização da objetividade material como também a satisfação das necessidades mais subjetivas dos jovens, como o desejo de pertencer e de participar das decisões que lhe dizem respeito.

Feita a discussão sobre os problemas referentes a uma orientação segura na compreensão da juventude no século XXI, subsiste a questão relativa às dificuldades que os jovens enfrentam na contemporaneidade, a começar pela própria garantia de que poderá realizar-se como pessoa, por meio de condições básicas que assegurem a sua existência.

Os dados analisados mostraram que os jovens estão bastante mais vulneráveis à violência, de modo que uma combinação de precariedade socioeconômica, dificuldade de inserção laboral e educacional e até mesmo o conflito geracional e a intolerância às formas contemporâneas de se manifestar como jovem configuram um quadro de desrespeito aos direitos básicos e de marginalização dos jovens, em alguns aspectos até mais que em outros períodos da história. Apontam, assim, para a afirmação da escola como uma necessidade para a inserção socioeconômica dos jovens. Também revelam, todavia, as dificuldades de se melhorar os indicadores e atender os jovens, conforme verificamos na falta de perspectiva das políticas públicas educacionais, que não atendem satisfatoriamente às necessidades, não ampliam as condições de oferta noturna de qualidade e optam pela terceirização com transferências de recursos para a iniciativa privada. Tais condições também ajudam a explicar a falta de adesão dos jovens às formas de sociabilidade pensadas para eles, pela via da educação e do trabalho, e aos projetos de futuro impostos pela sociedade.

Esses elementos todos mostram que, para a classe trabalhadora, as categorias juventude, escola e trabalho são indissociáveis, pois a relação dos jovens com a escola de Ensino Médio passa necessariamente pela relação com o trabalho e vice-versa. E nesse aspecto é preciso considerar não somente a falta de condições para que se acesse e se conclua o Ensino Médio, como também a falta de adesão ou interesse desses mesmos jovens pela escola e/ou pelo trabalho que lhes são oferecidos pela sociedade capitalista na atualidade.

Nesse sentido, se esses dois "mundos", do trabalho e da escola, são espaços importantes e complementares de realização da condição juvenil, o Ensino Médio carrega uma enorme 
potencialidade de contribuição para realização dos jovens como sujeitos históricos cujos direitos são pouco respeitados.

Os elementos teóricos e os dados estatísticos obtidos mostram que a realização da subjetividade juvenil não se limita à inclusão laboral, pois se assim o fosse a sociedade estaria diante de uma tragédia humana. Verificamos que, diante das dificuldades de inserção social pelo trabalho, conforme demonstram os altos índices de desemprego e as precárias condições laborais, é preciso refletir sobre os mecanismos desenvolvidos pelos próprios jovens para o enfrentamento dos condicionamentos sociais para a produção da sua materialidade e da sua imaterialidade.

No momento em que os valores cultuados pela sociedade capitalista não encontram mais o mesmo apelo junto aos jovens, é preciso conhecer os mecanismos de resistência juvenil ou de realização da sua subjetividade a partir dos nexos entre as perspectivas presentes nas políticas públicas, as alternativas de sociabilidade e sua condição concreta de vida, estudo e trabalho. Nesse sentido, os estudos sobre a/s juventude/s, as relações que estabelecem e os sentidos que atribuem à escola e ao trabalho deverão permanecer na agenda das políticas públicas e na pauta dos pesquisadores.

\section{REFERÊNCIAS}

BOX. Projeto sonho brasileiro: um estudo sobre o Brasil e o futuro a partir da perspectiva do jovem de 18 a 24 anos. 2011. Disponível em: http://pesquisa.osonhobrasileiro.com.br/indexn.php. Acesso em: 10 jun. 2016.

BRASIL. Câmara dos Deputados. Projeto de Lei no 8.035, de 20 dez. 2010. Aprova o Plano Nacional de Educação para o Decênio 2011-2020 e dá outras providências. Disponível em: http://www.camara.gov.br/ proposicoesWeb/fichadetramitacao?idProposicao=490116. Acesso em: 10 mar. 2016.

BRASIL. Lei Federal n 9.394, de 20 de dezembro de 1996. Estabelece as diretrizes e bases da educação nacional. D.O.U., Brasília, 23 dez. 1996. Disponível em: www.planalto.gov.br/ccivil_03/Leis/L9394.htm. Acesso em: 10 mar. 2016.

BRASIL. Lei Federal n. 12.852, de 05 de agosto de 2013. Institui o Estatuto da Juventude e dispõe sobre os direitos dos jovens, os princípios e diretrizes das políticas públicas de juventude e o Sistema Nacional de Juventude - SINAJUVE. D.O.U., Brasília, 06 ago. 2013. Disponível em: http://www.planalto.gov.br/ ccivil_03/_Ato2011-2014/2013/Lei/L12852.htm. Acesso em: 12 set. 2016.

BRASIL. Lei Federal n ${ }^{\circ} 12.858$, de 09 de setembro de 2013. Dispõe sobre a destinação para as áreas de educação e saúde de parcela da participação no resultado ou da compensação financeira pela exploração de petróleo e gás natural, com a finalidade de cumprimento da meta prevista no inciso VI do caput do art. 214 e no art. 196 da Constituição Federal; altera a Lei n ${ }^{0}$ 7.990, de 28 de dezembro de 1989; e dá outras providências. Brasília. Disponível em: http://presrepublica.jusbrasil.com.br/legislacao/1035999/lei-12858-13. Acesso em: 13 set. 2016.

BRASIL. Senado Federal. Estatuto da Juventude é sancionado pela presidente da República. Brasília. Disponível em: http://www12.senado.gov.br/noticias/materias/2013/08/05/estatuto-da-juventude-e-sancionadopela-presidente-da-republica. Acesso em: 12 set. 2016.

BRZEZINSKI, I. (Org.). LDB interpretada: diversos olhares se entrecruzam. São Paulo: Cortez, 1997.

CARRANO, P. C. R. O ensino médio na transição da juventude para a vida adulta. In: FERREIRA, C. A. (Org.). Juventude e iniciação científica: políticas públicas para o ensino médio. Rio de Janeiro: EPSJV, UFRJ, 2010. P. 143-168. 
CAMARANO, A. A.; KANSO, S. O que estão fazendo os jovens que não estudam, não trabalham e não procuram trabalho? In: Mercado de trabalho: conjuntura e análise. Brasília: IPEA - MTE, Nota Técnica $\mathrm{n}$. 53, 44 folhas, ano 17, nov. 2012.

CARTA CAPITAL. Um balanço do Plano Nacional de Educação. Fernando Vives. 28 out. 2012. Disponível em: http://www.cartacapital.com.br/carta-na-escola/um-balanco-do-plano-nacional-de-educacao/. Acesso em 28 out. 2016.

DAYRELL, J.; REIS, J. Módulo didático: sociologia da juventude - currículo básico comum - sociologia do ensino médio. Belo Horizonte: Centro de Referência Virtual do Professor - SEE-MG, set. 2010.

DIAS, F. S. A qualidade requerida da educação profissional técnica de nível médio. 2011. 162 folhas. Dissertação (Mestrado em Educação). Programa de Pós-Graduação em Educação, Universidade Federal de Minas Gerais, Belo Horizonte, 2011.

FREUD, S. Além do princípio de prazer. In: FREUD, S. Edição Standard Brasileira das Obras Psicológicas Completas de Sigmund Freud. Vol. XVIII. Rio de Janeiro: Imago, 1996.

GORZ, A. O envelhecimento. Tradução de Fernando Antonio Pinheiro Filho. Tempo Social. Revista de Sociologia da USP. São Paulo, p. 15-34, vol. 21, n. 1, jun. 2009.

HOPENHAYN, M. El encadenamiento educación y empleo: entre eslabón perdido y reproducción de las desigualdades. In: Tendencias en foco. Buenos Aires: RedETIS, IIPE-UNESCO. N. 22, Oct 2012. Disponível em: http://www.redetis.org.ar/media/document/enfoco22.pdf. Acesso em: 07 mar. 2016.

IBGE. Pesquisa Nacional por Amostra de Domicílio. PNAD 2015. Disponível em: http://www.ibge.gov.br/ home/estatistica/pesquisas/pesquisa_resultados.php?id_pesquisa=149. Acesso em: 30 nov. 2016.

INEP - INSTITUTO NACIONAL DE ESTUDOS E PESQUISAS EDUCACIONAIS ANÍSIO TEIXEIRA. Sinopses Estatísticas da Educação Básica. Brasília: MEC/INEP, anos diversos. Disponível em: http://portal. inep.gov.br/basica-censo-escolar-sinopse-sinopse. Acesso em: 30 abr. 2016.

INEP - INSTITUTO NACIONAL DE ESTUDOS E PESQUISAS EDUCACIONAIS. Indicadores Educacionais da Educação Básica/Taxas de Rendimento/ 2012. Brasília: INEP, 2012. Disponível em www.inep. gov.br. Acesso em: 30 abr. 2016.

INEP - INSTITUTO NACIONAL DE ESTUDOS E PESQUISAS EDUCACIONAIS. Censo Escolar da Educação Básica. Notas Estatísticas 2016. Brasília: INEP, 2016. Disponível em: http://files.comunidades. net/profemarli/censo_escolar_divulgacao_22032016.pdf. Acesso em: 22 fev. 2017.

INEP - INSTITUTO NACIONAL DE ESTUDOS E PESQUISAS EDUCACIONAIS. Diretoria de Estatísticas Educacionais. Panorama da Educação 2016. Brasília: INEP, 2016. Disponível em: http://www.publicacoes.inep.gov.br/portal/download/2005 Acesso em: 22 fev 2017.

IPEA - INSTITUTO DE PESQUISA ECONÔMICA APLICADA. Comunicado do IPEA n ${ }^{\circ}$ 76. Desemprego e desigualdade no Brasil metropolitano. Brasília: 10 fev. 2011a. Disponível em: http://www.ipea.gov. br/portal/images/stories/PDFs/comunicado/110210_comunicadoipea76.pdf. Acesso em: 10 abr. 2016.

IPEA - INSTITUTO DE PESQUISA ECONÔMICA APLICADA. Comunicado do IPEA n ${ }^{\circ} 124$. Financiamento da educação: necessidades e possibilidades. Brasília: 14 dez. 2011b. Disponível em: http://www.ipea. gov.br/portal/images/stories/PDFs/comunicado/111214_comunicadoipea124.pdf. Acesso em: 10 abr. 2016.

IPEA - INSTITUTO DE PESQUISA ECONÔMICA APLICADA. Comunicado do IPEA nº 142. Coabitação familiar e formação de novos domicílios nas áreas urbanas brasileiras. Brasília: 04 abr. 2012. Disponível em: http://www.ipea.gov.br/portal/images/stories/PDFs/comunicado/120404_comunicadoipea142. pdf. Acesso em: 10 abr. 2016. 
IPS - AGÊNCIA DE NOTÍCIAS INTER PRESS SERVICE. MARTIN, Megan. Primavera Árabe, jovens, liberdade e tecnologia. Califórnia, USA: 19 abr. 2012. Disponível em: http://ips.org/ipsbrasil.net/nota. php?idnews=8196. Acesso em: 16 fev. 2016.

KUENZER, A. Z. Da dualidade assumida à dualidade negada. O discurso da flexibilização justifica a inclusão excludente. Educação \& Sociedade. Campinas, n. 100, out 2007. Disponível em: http://www.scielo. br/pdf/es/v28n100/a2428100.pd Acesso em 28 nov 2016.

MASLOW, A. H. A theory of human motivation. 1943. Posted in August 2000. Disponível em: http://psychclassics.yorku.ca/Maslow/motivation.htm. Acesso em: 25 set. 2016.

NETTO, J. P.; BRAZ, M. Economia política: uma introdução. São Paulo: Cortez, 2006.

NOVA ESCOLA. Balanço do Plano Nacional de Educação (PNE) 2001-2010. Anderson Moço. São Paulo. Março 2010. Disponível em: http://revistaescola.abril.com.br/politicas-publicas/legislacao/pne-planonacional-de-educacao-537431.shtml. Acesso em: 27 out. 2016.

PAIS, J. M. Ganchos, tachos e biscates: jovens, trabalho e futuro. Porto, Portugal: Ambar, 2001.

RFI PORTUGUÊS. Blogueira baleada por talibãs no Paquistão vai ser tratada na Inglaterra. 15 out. 2012. Disponível em: http://www.portugues.rfi.fr/geral/20121015-blogueira-baleada-por-talibas-vai-ser-tratada-nainglaterra. Acesso em: 16 fev. 2016.

ROMÃO, J. E. Educação de jovens e adultos: problemas e perspectivas. In: GADOTTI, M.; ROMÃO, J. E. (Orgs.). Educação de jovens e adultos - teoria, prática e proposta. 7. ed. São Paulo: Cortez, 2005. P. 41-58.

SILVA, E. R. A.; ANDRADE, C. C. A política nacional de juventude: avanços e dificuldades. In: CASTRO, J. A.; AQUINO, L. M.; ANDRADE, C. C. de. (Orgs.). Juventude e políticas sociais no Brasil. Brasília: Ipea, 2009. P. 41-70.

SOARES, A. B. Juventudes e o mundo do trabalho: confinamento e a busca por pontes possíveis. Dossiê: classes sociais e transformações no mundo do trabalho. Mediações - Revista de Ciências Sociais, Londrina, Universidade Estadual de Londrina. p. 222-238, v. 16, n.1, jan./jun. 2011. Disponível em http://www. uel.br/revistas/uel/index.php/mediacoes/article/view/9660. Acesso em: 27 mai. 2016.

SPOSITO, M. P. Estado do conhecimento: juventude e escolarização. (publicação digital sem indicação de local e editora). 2000. Disponível em: http://www.educacao.salvador. ba.gov.br/site/documentos/espacovirtual/espaco-leituras/WEBTECA/estado $\% 20 \mathrm{do} \%$ 20conhecimento- $\% 20$ juventude $\% 20 \mathrm{e} \% 20$ escolarizacao. pdf Acesso em: 24 de mar. 2016.

STEIMBACH, A. A. Juventude, escola e trabalho: razões da permanência e do abandono no curso técnico em agropecuária integrado. 2012. 127 folhas. Dissertação (Mestrado em Educação). Programa de Pós-Graduação em Educação. Universidade Federal do Paraná. Curitiba, 2012.

TARGINO, R.; SMOSINSKI, S. Estudante de 13 anos de SC cria página no Facebook para relatar problemas da escola. UOL Educação, São Paulo, 27 ago. 2012. Disponível em: http://educacao.uol.com.br/ noticias/2012/08/27/estudante-de-13-anos-de-sc-cria-pagina-no-facebook-para-relatar-problemas-da-escola. htm. Acesso em: 16 fev. 2016.

WAISELFISZ, J. J. Mapa da violência no Brasil 2012: os novos padrões da violência homicida no Brasil. São Paulo: Instituto Sangari, 2012.

SPOSITO, M. P.; CARRANO, P. C. R. Juventude e políticas públicas no Brasil. Revista Brasileira de Educação. Rio de Janeiro, ANPEd, n. 24, p. 16-39, Set./Out./Nov./Dez. 2003.

Artigo recebido em: $12 / 03 / 2017$ Aprovado em: 08/05/2017 


\section{CONTATO PARA CORRESPONDÊNCIA:}

Márcio Luiz Bernardim. E-mail: marcio.bernardim@gmail.com

NOTAS

1 Muitas entidades e lideranças comprometidas com a democratização da educação brasileira criaram o Fórum Nacional em Defesa da Escola Pública no processo político de formulação da LDBEN, que funcionou por quase uma década, num processo democráti co de discussão das propostas surgidas dos debates, para fazer acolher na instância legislativa os interesses da população e dos órgãos que congregam os educadores e os especialistas em educação no Brasil. Esses anseios se consubstanciaram no Projeto Jorge Hage, que levava o nome do seu relator na Câmara dos Deputados, mas foram totalmente ignorados por meio do que se chamou de "golpe de relatoria" do então Senador Darcy Ribeiro, que desconsiderou toda a construção democrática feita até então e resgatou o seu projeto de lei, de interesse do governo e da ala conservadora que lhe dava sustentação. (BRZEZINSKI, 1997; ROMÃO, 2005). 